\title{
University of Maryland Marlene and Stewart Greenebaum Cancer Center
}

National Cancer Institute

\section{Source}

National Cancer Institute. University of Maryland Marlene and Stewart Greenebaum

Cancer Center. NCI Thesaurus. Code C105628.

The mission of the University of Maryland Marlene and Stewart Greenebaum Cancer Center is to conduct innovative basic and clinical research that will impact the understanding and treatment of cancer around the world and to provide state-of-the-art clinical care to cancer patients in Maryland and beyond. It became an $\mathrm{NCl}$-designated cancer center in 2008. Its parent institutions include University of Maryland School of Medicine and University of Maryland Medical System. 